\title{
Random oscillation patterns with stimulation of a single brain site
}

\author{
JOHN GAITO and JOSÉ N. NOBREGA \\ York University, Downsview, Ontario, Canada M3J 1 P3
}

\begin{abstract}
Previous research had indicated that an oscillation effect resulted during sequential alternation of unilateral amygdaloid stimulation with consistent low values for one side and consistent high values for the contralateral one. In the present study with two experiments, stimulation was of a single amygdaloid site over 10 phases of six clonic convulsions. The frequency of oscillation patterns was not greater than that expected by chance in the latency measure, which suggested that the oscillation effect results from the interaction between the homologous brain sites during the kindling process.
\end{abstract}

The "kindling effect" has been investigated in a number of laboratories as a model of learning, a model of epilepsy, or as an example of behavioral change of interest in its own right (e.g., Gaito \& Gaito, 1974; Goddard, McIntyre, \& Leech, 1969). This event involves a change from normal exploration to automatic behaviors and, finally, to clonic convulsions in response to electrical stimulation of a specific brain site (e.g., amygdala).

In recent research in our laboratory using a sequence of alternating unilateral stimulation of the amygdala, an "oscillation effect" was observed (Gaito, 1976). This oscillation usually consisted of low values for the amygdala first stimulated (primary site) and high values for the contralateral amygdala (secondary site). The effect was most prominent in latency data (number of seconds from onset of stimulation to onset of convulsion). The oscillation tendency in latency data has been remarkably resistant to a number of experimental manipulations (Gaito, Gaito, \& Nobrega, 1977).

One possible basis for this effect is that the apparent systematic patterns are of chance nature. With our procedure of alternating stimulations over 10 phases and our requirement that a rat must show a consistent "low-high" or "high-low" pattern for at least 8 of the 10 alternating phases to be designated as an "oscillator," the probability that these apparent systematic patterns of oscillations are actually random ones is .17 based on the one sample runs procedure (Hoel, 1954). ${ }^{1}$ In each experiment conducted so far, the number of oscillators observed in the latency measure was significantly different from that expected by chance.

It is possible to determine empirically the probability of an oscillation pattern by chance. This method involves the application of stimulation to the same site over 10 phases and was the procedure of concern in the two experiments of the present study.

\section{EXPERIMENT 1}

\section{Method}

In both experiments male Wistar rats were implanted bilaterally with bipolar electrodes in each amygdala. The brain coordinates for electrode implantation were the same as in previous experiments: $.5 \mathrm{~mm}$ posterior to bregma, $4.5 \mathrm{~mm}$ from midline, $8.5 \mathrm{~mm}$ from skull (Gaito, 1976; Gaito \& Gaito, 1974).

Stimulation trials began a week or more after electrode implantation. Each trial consisted of passing a $60-\mathrm{Hz}$ sine wave for $30 \mathrm{sec}$ into the rat, using a Lafayette stimulator. The initial intensity was set at 100 microA for all animals; the current was gradually increased in the cases of no clonic convulsion (CC) by 10 trials until the appropriate intensity was achieved for each animal. In most cases the convulsion was achieved with 100 microA, and in no case was the intensity level raised beyond 420 microA.

For each rat the behavioral designation for the latency and criterion measures was that of primary oscillator, secondary oscillator, or nonoscillator. For example, to be classified as an oscillator the rat had to show a consistent pattern of "low-high" (primary oscillation) or "high-low" (secondary oscillation) in latency and/or criterion data over 8 or 10 of the 10 alternation phases. As in the previous research, duration values were not analyzed.

In Experiment 1 there were 12 male Wistar rats (approximately 130 days of age at the beginning of the experiment). Each phase of the 10 involved stimulation of one side only (side chosen randomly) to the criterion of six CCs.

\section{Results}

In this experiment there were 12 nonoscillators in criterion data and 10 nonoscillators, one primary oscillator, and one secondary oscillator in the latency measure (Table 1). Neither of these observed numbers of oscillators, zero and two, was significantly different from the number expected (two) using the binomial distribution with the probability of oscillation set at .17 $(\mathrm{p}>.05)$.

Table 2 shows typical values for two rats in Experiment 1 . The first rat shows a secondary oscillation pattern in latency data; the second is a nonoscillator in both measures. 
Table 1

Frequency of Different Behavioral Patterns of Rats in Experiments 1 and 2

\begin{tabular}{|c|c|c|c|c|c|c|c|c|c|c|c|c|}
\hline & \multirow{2}{*}{\multicolumn{3}{|c|}{$\frac{\text { Experiment } 1}{\text { Unilateral }}$}} & \multicolumn{6}{|c|}{ Experiment 2} & \multirow{2}{*}{\multicolumn{3}{|c|}{$\begin{array}{c}\text { Combined } \\
\text { Unilateral } \\
\text { Groups }\end{array}$}} \\
\hline & & & & \multicolumn{3}{|c|}{ Bilateral } & \multicolumn{3}{|c|}{ Unilateral } & & & \\
\hline & NO & PO & SO & & $\mathrm{PO}$ & SO & NO & PO & SO & NO & PO & SO \\
\hline Latency & 10 & 1 & 1 & 0 & 3 & 3 & 8 & 1 & 2 & 18 & 2 & 3 \\
\hline Criterion & 12 & 0 & 0 & 5 & 1 & 0 & 11 & 0 & 0 & 23 & 0 & 0 \\
\hline
\end{tabular}

\section{EXPERIMENT 2}

\section{Method}

It is possible that an oscillation effect might be generated over 10 phases of stimulation of a single side if sufficient time were available following each phase. With alternation of stimulation from one side after six CCs to the other in the previous research, there were always at least two days of nonstimulation of one side prior to the next phase of stimulation of that side when three trials each day were used. Thus, Experiment 2 inserted rest phases between each stimulation phase. The exact days of rest were determined from the results of earlier research; 3 days were used between phases up through Phase 5, and 2 days was the rest interval thereafter.

The other procedures were the same as in Experiment 1. Eleven male Wistar rats were used for the unilateral stimulation group. Six other male Wistar rats were treated as in previous studies: One side was stimulated to six CCs; then the contralateral amygdala was stimulated to the same criterion; then stimulation was applied again at the primary site, etc. (bilateral stimulation group).

The brains of the rats in these two groups were frozen and 50 -micron sections were mounted on slides. These slides were examined under a magnifying lens. The electrode tips of 9 of the 11 rats in the unilateral group were in the amygdala. The other two rats had electrode tips in the boundary between the amygdala and the caudate putamen-globus pallidus. Both electrodes for five of the six bilateral rats were in the amygdala. The sixth rat had one electrode in the amygdala and the other in the ventral caudate-putamen, adjacent to the amygdala.

\section{Results}

The rest interval inserted between phases had no effect on the results; only three rats oscillated in the latency dependent variable and none in criterion data (Table 2). Neither of these values was significantly different from 1.9 , the number expected by chance using the binomial distribution $(\mathrm{p}>.05)$.
In the latency data the result of six oscillators of the six bilateral rats was significantly different from the one oscillator expected $(\mathrm{p}<.05$; the exact $\mathrm{p}=.000048$, twotailed value). But the observed value of one in criterion data with this group was not significantly different from the number expected by chance. Results with this group were consistent with those obtained in previous experiments. Typical values are shown in Table 2 for Rat 3 . This animal shows primary oscillation in both latency and criterion measures.

The unilateral groups were combined, providing five oscillators (of 23 rats) in latency data and no oscillators in the criterion measure. Using the binomial distribution, this latency value was not significantly different from that expected by chance $(3.9)^{2}$. However, the criterion value of 0 was significantly less than expected $(p<.05)$. This latter result is probably based on the fact that many rats show no variability after a few phases, inasmuch as the criterion is reached in six trials. Thus, from a practical viewpoint, for most rats there are not really 10 phases in which to show some variability.

\section{GENERAL DISCUSSION}

These experimental results are consistent with those based on the statistical determination of the probability of an oscillation pattern by chance using the one sample runs procedure; they show that the $p$ of .17 is an adequate estimate. Also, these results seem to indicate clearly that the oscillation effect is a bilateral event. In Experiments 1 and 2 with unilateral stimulation, oscillation patterns were not present to the same degree as that found in previous research when stimulation was bilateral on successive phases. However, alternation of stimulation from primary to secondary sites in Experiment 2 with the bilateral stimulation group produced patterns of oscillation comparable to those observed in previous research.

An interesting aspect observed in these experiments was that the variability between phases for the unilateral rats was less than for bilateral animals (see Table 2). The degree of variability between the 10 phases for unilateral rats appears to be more similar to the variability between the five primary site phases and that between the five secondary site phases for the bilateral group. This aspect probably reduces the possibility of meeting our criterion for oscillation.

To account for the oscillation effect in the bilateral rats of Experiment 2 and in previous research, presumably there are some inhibitory and/or facilitatory effects from the primary site to the secondary site, and vice versa. However, it is not clear what the exact basis for the effect is. A pattern appears to be

Table 2

Typical Responses for Latency and Criterion Measures in Experiment 1 and for a Bilateral Rat in Experiment 2 (Number 3)

\begin{tabular}{|c|c|c|c|c|c|c|c|c|c|c|c|}
\hline \multirow{2}{*}{$\begin{array}{c}\text { Rat } \\
\text { Number }\end{array}$} & & \multicolumn{10}{|c|}{ Phases } \\
\hline & & 1 & 2 & 3 & 4 & 5 & 6 & 7 & 8 & 9 & 10 \\
\hline 1 & $\begin{array}{l}\text { Latency } \\
\text { Criterion }\end{array}$ & $\begin{array}{l}4.2 \\
6\end{array}$ & $\begin{array}{l}3.5 \\
6\end{array}$ & $\begin{array}{l}3.7 \\
6\end{array}$ & $\begin{array}{l}3.5 \\
6\end{array}$ & $\begin{array}{l}4.2 \\
6\end{array}$ & $\begin{array}{l}2.3 \\
6\end{array}$ & $\begin{array}{l}6.3 \\
6\end{array}$ & $\begin{array}{l}3.5 \\
6\end{array}$ & $\begin{array}{l}2.5 \\
6\end{array}$ & $\begin{array}{l}1.0 \\
6\end{array}$ \\
\hline 2 & $\begin{array}{l}\text { Latency } \\
\text { Criterion }\end{array}$ & $\begin{array}{l}6.7 \\
14\end{array}$ & $\begin{array}{l}4.8 \\
6\end{array}$ & $\begin{array}{l}4.8 \\
6\end{array}$ & $\begin{array}{l}5.3 \\
6\end{array}$ & $\begin{array}{l}7.3 \\
7\end{array}$ & $\begin{array}{l}6.3 \\
6\end{array}$ & $\begin{array}{l}6.7 \\
6\end{array}$ & $\begin{array}{l}7.8 \\
6\end{array}$ & $\begin{array}{l}7.2 \\
6\end{array}$ & $\begin{array}{l}7.5 \\
6\end{array}$ \\
\hline 3 & $\begin{array}{l}\text { Latency } \\
\text { Criterion }\end{array}$ & $\begin{array}{l}8.0 \\
12\end{array}$ & $\begin{array}{l}19.2 \\
19\end{array}$ & $\begin{array}{l}3.7 \\
6\end{array}$ & $\begin{array}{l}14.3 \\
15\end{array}$ & $\begin{array}{l}5.0 \\
6\end{array}$ & $\begin{array}{l}14.7 \\
11\end{array}$ & $\begin{array}{l}6.8 \\
6\end{array}$ & $\begin{array}{c}15.5 \\
7\end{array}$ & $\begin{array}{l}7.7 \\
7\end{array}$ & $\begin{array}{c}15.0 \\
6\end{array}$ \\
\hline
\end{tabular}


set up, either primary oscillation or secondary oscillation, during Phases 1 and 2 , or by Phases 3 and 4 , and most rats continue with this pattern for the remainder of the 10 phases. In one experiment in which rats were stimulated for 50 phases, some rats showed a consistent pattern of oscillation for the 50 phases (Gaito, in press).

The unilateral sequential alternation procedure and the resulting oscillation effect appear to be useful for obtaining information on some aspects of the events underlying the kindling effect; for example, possible differential electrical synaptic patterns related to the difference in latency values for the primary and secondary sites. Because kindling shows many parallels to learning and to epilepsy, and can be considered as a model of consistent behavioral changes in response to an invariant stimulus, experimentation with the oscillation effect may have the potential for providing information relevant to brain function in general.

\section{REFERENCES}

GAITo, J. An oscillation effect during sequential alternations of unilateral amygdaloid stimulations within the kindling paradigm. Physiological Psychology, 1976, 4, 303-306.

GaIto, J., \& GaITo, S. T. Interanimal negative transfer of the kindling effect. Physiological Psychology, 1974, 2, 379-382.

Gaito, J.. Gaito, S. T., \& Nobrega, J. N. A factor analysis of data from 10 phases of sequential alternations of amygdaloid stimulation within the kindling paradigm. Physiological Psychology, 1977, 5, 300-310.

GaIto, J. The oscillation effect over long-term periods. Bulletin of the Psychonomic Society, in press.

Goddard, G. V., McIntyre, D. C., \& LeECh, C. K. A permanent change in brain function resulting from daily electrical stimulation. Experimerital Neurology, 1969, 25, 295-330.

HoEl, P. G. Introduction to mathematical statistics. New York: Wiley, 1954.

\section{NOTES}

1. The hypothesis that the oscillation patterns are random ones can be assessed by the one sample runs test (Hoel, 1954). Using the requirement of 8 or 10 phases of oscillation out of 10 phases would provide 8,9 , or 10 runs. The p of 8,9 , and 10 runs is $.1270, .0317$, and .0079 , respectively; the $p$ of 8,9 , or 10 runs is the sum of these ps, .1666 or .17 . Thus the $p$ that these apparent systematic patterns are random ones would be .17 .

2 . In other research underway at the present time, a unilateral group of 12 rats was used as a control group. Two of the 12 showed an oscillation pattern. This number was not significantly different from the number expected, two. With this group and the two used in the present study, there were 7 oscillators in 35 rats, a number not significantly different from the 6 expected.

(Received for publication September 19, 1977.) 